Perceptions of Psychological Well-being in UK Law Academics

J. CLARE WILSON* AND CAROLINE STREVENS**

* Department of Psychology, University of Portsmouth, Portsmouth, P01 2DY, England

Clare.wilson@port.ac.uk

** Portsmouth Law School, University of Portsmouth PO12DY, England

Caroline.strevens@port.ac.uk 


\title{
Perceptions of Psychological Well-being in UK Law Academics
}

\begin{abstract}
This study provides evidence that changing and increasing expectations of University, of students, and of academics of themselves has had an impact upon the perceptions of wellbeing in the Law Teachers who responded to this survey.

A total of 185 UK Law Teachers completed a large survey which included demographic questions (age, academic qualifications, and experience), four questionnaires and a series of open-ended questions. Although most reported depression, anxiety and stress levels within the normal range, those who reported high stress levels were significantly more likely to report lower hope scores and higher obstruction of values scores as well as significantly less environmental mastery and self-acceptance. The results reported here indicate the importance of autonomy to Law Teachers. It is suggested that this is an issue that requires further investigation because of the potential for levels of psychological distress to increase.
\end{abstract}

Keywords: Law Teachers; psychological well-being; self -determination theory; academics 


\section{INTRODUCTION}

Student mental health and well-being has become a growing concern in the $\mathrm{UK}$, and, in particular, concern for law students was raised when Australian and American research demonstrated abnormally high stress levels in this group. ${ }^{1}$ Baron made a plea for Australian Law Schools to consider law academics. She suggested that "we need to start taking the well-being of law staff seriously if we are interested in the health and well-being of the legal profession more generally."2

However, little research to date has explored the expectations of academic staff in dealing with stressed students or the implications for their own well-being. This paper argues that, if Universities are to support students and academics, it is crucial to understand how staff understand and manage their own psychological wellbeing.

Academic staff are a surprisingly under-researched group. A European survey by Hohle \& Teichler $^{3}$ indicated British academics were the least satisfied with their jobs compared with their European counterparts despite being relatively highly paid (although well-being per se was not explored in this study). Kwiek and Antonowicz, ${ }^{4}$ reporting on this data, suggested that the marked and continual change in Higher Education across Europe over the last 20 years may help explain it. They cite the 5 drivers from Enders and De Weert as:

"massification of higher education, expansion of research, growing emphasis on the societal relevance of higher educational and research, globalisation and

\footnotetext{
${ }^{1}$ R. Field, J. Duffy, and A. Huggins, 'Teaching independent learning skills in the first year: A positive psychology strategy for promoting law student well-being’ (2015) 8(2) Journal of Learning Design, 110.

${ }^{2}$ P. Baron, 'Thriving in the Legal Academy' (2007) 17,27 Legal Education Review p52

${ }^{3}$ U. Teichler, and E. Höhle, (Eds.), The work situation of the academic profession in Europe: Findings of a survey in twelve countries. (2013)

${ }^{4}$ M. Kwiek, and D. Antonowicz, D. 'Academic work, working conditions and job satisfaction' in The work situation of the academic profession in Europe: Findings of a survey in twelve countries, ed. U. Teichler and E. Hohle 37-54
} 
internationalisation and marketization policies and practices, and managerialism."

The picture in the UK is most concerning. $61 \%$ senior and $56 \%$ junior academics in the UK see their job as a source of strain. ${ }^{6}$

In a report that covered only the UK, Kinman and $\mathrm{Wray}^{7}$ reported that "On all but one of the Health and Safety Executive stressor categories, [respondents] in higher education reported lower well-being than the average for those working in the target group industries (including education)". The changes in working context that impinge on academic well-being have been evaluated by $\mathrm{Kinman}^{8}$ and have led to a call for more research to inform implementation of strategic interventions for the sector.

More recently a research report, published by Student Minds ${ }^{9}$ using a qualitative research methodology, looked at the role of academics in responding to student mental health issues. The report by Hughes, Panjwani, Tulcidas and Byrom , entitled 'Student Mental Health: The Role and Experience of Academics' (herein The Student Mental Health Report) did not directly address the well-being of academics but made a number of recommendations to improve support for students and staff by, amongst others issues, clarification of the pastoral care role of the academic.

\footnotetext{
${ }^{5}$ J. Enders, \& E. de Weert, 'Towards a t-shaped profession: Academic work and career in the knowledge Society' in The changing face of academic life: Analytical and comparative perspectives eds

J. Enders \& E. de Weert (2009) pp. 251-272

${ }^{6}$ Kwiek, op. cit., n4, p49

${ }^{7}$ G. Kinman, and S.Wray, 'Higher stress. A survey of stress and well-being among staff in higher education. (2013) University and College Union at p2 see

$<$ https://www.ucu.org.uk/media/5911/Higher-stress-a-survey-of-stress-and-well-being-among-staff-inhigher-education-Jul-13/pdf/HE_stress report_July_2013.pdf $>$ accessed 20/2/18

${ }^{8}$ G. Kinman 'Doing more with less? Work and well-being in academics' (2014)4(2) Somatechnics, 219-235.

9 G. Hughes et al. "Student mental health: The role and experiences of academics." (2018). See <http://www.studentminds.org.uk/theroleofanacademic.html> Accessed 20/2/18. Student Minds describes itself as the UK Student's Mental health Charity. It is a charitable company established in 2011 with the aim of working "with students, service users, professionals and academics to develop new and innovative ways to improve the mental health of students." This includes commissioning research in order to support evidenced-based lobbying for change.
} 
For the purposes of the present paper, psychological well-being will be explored and will be taken to include general psychological well-being, living according to one's values, hope, depression, anxiety and stress.

First, one of the most robust models of psychological well-being was developed by Ryff in 1989, and this model has six factors. ${ }^{10}$ A questionnaire was developed to measure psychological well-being with the six factors represented by six subscales on the questionnaire. The first factor is autonomy, which explored selfdetermination (for example, a high score suggests that one is an independent thinker, whereas a low score may indicate more conformity to social situations). The second factor is environmental mastery, which explores the ability to manage environments according to ones' needs and values (for example, a high score may indicate a sense of mastery over opportunities and situations whereas a low score may indicate difficulty coping with daily demands and feeling out of control in relation to external demands). The third factor is personal growth, which is enjoying new experiences that are of challenge (eg, a high score may indicate the participant enjoys learning and developing their self-knowledge whereas a low score suggests personal stagnation). The fourth factor is positive relations with others, which is enjoying connecting with other people (eg, a high score may indicate warm and satisfying relationships with others whereas a low score may indicate isolation). The fifth factor is purpose in life, which focuses on having goals and plans for the future (a high scorer is likely to be very goal directed, and moving in a meaningful direction whereas a low scorer may lack a sense of direction). The final factor is self-acceptance, which focuses on liking the self (eg, a high scorer can acknowledge both their good and bad qualities and feel

\footnotetext{
10 C. D. Ryff, and C.L.M. Keyes, 'The structure of psychological well-being revisited' (1995) 69(4)
} Journal of personality and social psychology, 719. 
good about themselves overall whereas a low scorer would rather be someone else). This model and scale has been widely used and validated ${ }^{10}$.

Second, an awareness of one's values helps one maintain mental health. For example, Krieger ${ }^{11}$ argued that the pressures to succeed which occur at law schools tended to direct students away from positive personal (intrinsic) values and towards more external recognition, and rewards. This movement away from intrinsic values is strongly related to a loss of well-being and life satisfaction. Indeed, Deci and Ryan ${ }^{12}$ found that students who pursue extrinsic values such as image, money, and fame demonstrated poorer psychological well-being compared to those who pursue intrinsic values such as personal growth. This is due in part to pursuing (extrinsic) values that were beyond personal control. The present study explores values from the perspective of either progressing towards one's values or feeling obstructed in achieving one's values (that is, not making progress towards personal values) rather than in specific values per se.

The third aspect is hope. Snyder defined hope as 'a positive motivational state that is based on an interactively derived sense of successful (a) agency (goal-directed energy) and (b) pathways (planning to meet goals) ${ }^{13}$ Hope can provide a model for understanding and explaining cognitive approaches to motivation and goal setting. ${ }^{14}$ Martin and Rand referring to Snyder et $\mathrm{al}^{15}$ (2002) note the following characteristics that tend to be found in people who have hope: First, 'Hope has been shown to

\footnotetext{
${ }^{11}$ L. S. Krieger, 'What we're not telling law students-and Lawyers-that they really need to know: Some thoughts-in-action toward revitalizing the profession from its roots' (1998) $13 \mathrm{JL} \&$ Health 1.

12 E. L. Deci, and R. M. Ryan, 'The 'what' and 'why' of goal pursuits: Human needs and the selfdetermination of behaviour' (2000) 11(4) Psychological Inquiry 227-268.

13 C. R. Snyder, L Irving and J.R. Anderson, 'Hope and Health: Measuring the Will and the Ways' in Handbook of Social and Clinical Psychology: The Health Perspective eds C. R. Snyder \& D.R. Forsyth (1991) pp285-305.

${ }^{14}$ A. D. Martin \& K. L. Rand, 'The Future's So Bright, I Gotta Wear Shades: Law School Through the Lens of Hope'(2010) 48 Duquesne Law Review, 203 at p207

15 C. R. Snyder, H. S. Shorey, J. Cheavens, K. M. Pulvers, V. H. Adams III, \& C. Wiklund, 'Hope and academic success in college' (2000) 94(4) Journal of educational psychology 820.
} 
positively correlate with self-esteem, perceived problem-solving abilities, perceptions of control, and positive affect'. ${ }^{16}$ Second, 'High-hope persons tend to experience better mental health'. ${ }^{17}$ Third, people with hope have 'greater pain tolerance', ${ }^{18}$ and recover better from illness and injury. ${ }^{19}$ Fourth, hope has also correlated positively with social competence and social awareness. ${ }^{20}$

Fourth, the three main areas of mental health that relate to aversive experiences explored in the current paper are depression, anxiety and stress. The Diagnostic and Statistical Manual of Mental Disorders, $5^{\text {th }}$ edition $(D S M-V){ }^{21}$ defines the category of Major Depressive Disorder as where the following symptoms are present more often than not over a prolonged period of time: fatigue, sleep disturbances, inability to concentrate, and physical restlessness, amongst others. However, generally the public defines any prolonged period of low mood as depression.

Anxiety is often seen as excessive, uncontrollable worrying about aspects of life. As a group of disorders, they are defined in the DSM-V as: Anxiety Disorders; Obsessive-Compulsive and Related Disorders; and Trauma- and Stressor-Related Disorders. $^{22}$

Stress (as opposed to anxiety) is usually defined as a specific reaction to an event (stressor) in the environment. For example, one may be anxious about the future

\footnotetext{
${ }^{16}$ Snyder, id.

17 Snyder, id referring to K. M. Cramer and L D.yrkacz, 'Differential Prediction of Maladjustment Scores with the Snyder Hope Subscales' (1998) 83 Psychology Reports 1035.

18 Snyder, id referring to C R Snyder et al, 'Hope Against the Cold: Individual Differences in Trait Hope and Acute Pain Tolerance on the Cold Pressor Task' (2005) 73 Journal of Personality 287.

19 Snyder, id referring to D.D. Barnum et al, 'Hope and Social Support in the Psychological Adjustment of Children Who Have Survived Burn Injuries and their Matched Controls' (1998) 27 Children's Health Care 15; Timothy R Elliot et al, 'Negotiating Reality After Physical Loss: Hope, Depression, and Disability' (1991) 61 Journal of Personality and Social Psychology 608.

${ }^{20}$ Snyder, id referring to C R Snyder et al, 'Hope Theory, Measurements, and Applications to School Psychology' (2003) 18 School Psychology Quarterly 122, 126.

${ }^{21}$ DSM-V; American Psychiatric Association, 2013

${ }^{22}$ Id.
} 
and stressed about completing a grant application on time. Stress and anxiety can lead to social withdrawal, irritableness, fatigue and low self-esteem, as well as physical reactions, for example, an increased risk of heart disease and maladaptive behavioural responses such as increased smoking or drinking, or extreme weight loss or gain. ${ }^{23}$ In the workplace, 'Burnout' is considered to be a response to chronic stress. ${ }^{24}$ The scale used to explore these is the Depression, Anxiety and Stress Scale, which was designed to measure these three factors in non-clinical populations as well as use to screen clinical populations. $^{25}$

All of these factors were explored together to get a broad understanding of overall well-being. Further, a number of open-ended questions were designed to ascertain the participants understanding of their own and their students' well-being. Thus, the current research had three main objectives: first, to detail law teachers overall psychological well-being. Second, to explore how they experience and maintain their own well-being. Third, to explore how they may seek to maintain the psychological well-being of their students. Consequently the online survey consisted of five main sections: Ryff's well-being scale; the Depression, Anxiety and Stress Scale- DASS-21; the Valuing Questionnaire; the Adult Hope Scale and the open ended questions.

\section{METHOD}

\section{Design}

\footnotetext{
${ }^{23}$ H. K. Jensen, J. Wieclaw, T. Munch-Hansen, A. M. Thulstrup, J. P. \& Bonde 'Does dissatisfaction with psychosocial work climate predict depressive, anxiety and substance abuse disorders? A prospective study of Danish public service employees' (2010) 64(9) Journal of Epidemiology and Community Health, 796-801

${ }^{24}$ O. Hellesøy, K.Grønhaug, and O. Kvitastein, 'Burnout: conceptual issues and empirical findings from a new research setting' (2000) 16(3) Scandinavian journal of management 233-247.

${ }^{25}$ P. F. Lovibond, and S. H. Lovibond. 'The structure of negative emotional states: Comparison of the Depression Anxiety Stress Scales (DASS) with the Beck Depression and Anxiety Inventories' (1995) 33.3 Behaviour research and therapy 335-343.
} 
A questionnaire design was used in the current study. The independent variable were the age and experience of the law academics, and the dependent variables were depression, anxiety, stress, values, hope, autonomy, environmental mastery, personal growth, positive relations with others, purpose in life and selfacceptance.

\section{Participants}

Of the 185 participants who completed the survey, 125 (68\%) were female, and $59(32 \%)$ were male. $149(80 \%)$ were full time and $36(20 \%)$ were part-time. The average Age was 46 years, (SD $=10$ years and an age range of 26-69 years). On average, teachers taught 255 hours per academic year (although there was a wide variation, as some taught mainly tutorials and others taught multiple units with large $200+$ classes) .

\section{Materials}

The present research created a large survey using demographic questions (age, academic qualifications, and experience), four psychometrically sound scales and a series of open-ended questions asking about personal definitions of stress and wellbeing as well as how well law teachers feel they can cope with student demands for help in this area.

(a) Depression, Anxiety and Stress Scale -21 (DASS-21) ${ }^{26}$ This scale contained three self-report subscales for depression, anxiety and stress. Participants rated a series of statements for how much they applied to them in the past week, using a 4 point scale (0 -did not apply to me at all, to 3 -applied to me very much or most of the time). The scores for stress, depression and anxiety were then calculated by summing the scores

\footnotetext{
${ }^{26}$ Antony, op. cit., n.22 for the original 42-item scale, and see Lovibond, id.
} 
(and multiplying them by 2 to compare to the 42 item scale). The subscales in the current study showed good internal consistency, with Cronbach's alpha for

Depression $=0.94$; Anxiety $=0.84$; and Stress $=0.91$ al being with the acceptable range . (b) Valuing Questionnaire. ${ }^{27}$ This consists of 10 -items that explore how much one is living according to one's values (rather than exploring specific values). Statements were rated from 0 (not at all true) to 6 (completely true). There are two subscales: Progress towards one's values (Cronbach's alpha for the current study $=.84$ ) and Obstruction towards one's values (alpha $=.81)$.

(c) Psychological Well-Being Scale (PWBS) ${ }^{28}$ : This is an 84 item scale that measures six (each containing 14 statements) dimensions of psychological well-being: autonomy, environmental mastery, personal growth, positive relations with others, purpose in life and self-acceptance. Each statement is rated on the Likert scale, ranging from 1 (strongly disagree) to 6 (strongly agree). The Cronbach's alphas for the subscales all showed good reliability: autonomy (.79), environmental mastery (.89), personal growth (.88), positive relations with others (.87), purpose in life (.90) and self-acceptance (.93).

(d) The Adult Hope Scale ${ }^{29}$ (Snyder et al, 1991). This is a self-report measure designed to measure a person's current goal directed thinking. Participants rate how accurately each item describes them on a Likert scale, ranging from 1 (definitely false) to 8 (definitely true). The scale has two subscales: Agency (4 items), which refers to the perceived capability to achieve one's goals, and Pathway (4 items), which refers to the production of a plausible route to achieve said goals. The

\footnotetext{
${ }^{27}$ M. Smout, et al. 'Development of the valuing questionnaire (VQ)' (2014) 3.3 Journal of Contextual Behavioral Science 164-172.

${ }^{28}$ C. D. Ryff, 'Happiness is everything, or is it? Explorations on the meaning of psychological wellbeing' (1989) 57(6) Journal of personality and social psychology 1069

${ }^{29}$ C. R. Snyder, et al. 'The will and the ways: Development and validation of an individualdifferences measure of hope' (1991) 60.4 Journal of personality and social psychology 570.
} 
remaining 4 items are simply distractors. The present study produced a Cronbach's alpha of $=.85$ for the Agency Subscale and of $=.83$ for the Pathway subscale.

\section{Procedure}

Prior to submitting the surveys, ethical approval was sought from the Portsmouth Business School ethics committee. The surveys were distributed online (using Qualtrics) over the summer period (a lighter teaching time for staff, with the hope that participants would have more time to complete the surveys). All law teachers were emailed the link via the four legal Scholarly associations: The Committee of Heads of University Law Schools, The Society of Legal Scholars, The Association of Law Teachers, and the Socio-Legal Studies Association. All participants were informed about confidentiality and anonymity. There was also a debrief sheet at the end of the survey explaining potential sources of help should participants feel they needed it. The online survey was available for one month, after which it was closed, downloaded, collated and analysed using SPSS software.

\section{RESULTS}

First, preliminary correlations were conducted. Pearson's correlations were used to explore the relationships between the totals DASS, the Adult Hope scale, the Ryff Well-being scale, and the Valuing scale in this sample (see Table 1). Results indicate a strong significant negative relationship between all the DASS subscales and most of the positive well-being subscales. Of note is that the strongest (and positive) correlations with the DASS subscales is with Obstructing Values. 
Table 1: Pearson Correlations between the DASS and Well-being Scores

\begin{tabular}{llll}
\hline & Stress & Anxiety & Depression \\
\hline Agency Hope & -.419 & $-.348^{* *}$ & -.560 \\
Pathway Hope & $-.410^{* *}$ & $-.295^{* *}$ & $-.474 * *$ \\
Progress Values & $-.428^{* *}$ & $-.306^{* *}$ & $-.463 * *$ \\
Obstruct Values & $.757^{* *}$ & $.651^{* *}$ & $.733^{* *}$ \\
Autonomy & $-.393^{* *}$ & $-.411^{* *}$ & $-.364 * *$ \\
Environ Mastery & $-.611^{* *}$ & $-.526^{* *}$ & $-.653^{* *}$ \\
Personal Growth & -.159 & -.110 & $-.256^{* *}$ \\
Positive Relations & $-.310^{* *}$ & $-.221^{*}$ & $-.321 * *$ \\
Purpose in Life & $-.384 * *$ & $-.427^{* *}$ & $-.617 * *$ \\
Self-Acceptance & $-.478^{* *}$ & $-.526^{* *}$ & $-.663^{* *}$ \\
\hline
\end{tabular}

Note. Significance level ${ }^{*} p<.05,{ }^{* *} p<.01$ (significance means that the scores are highly unlikely to be due to chance alone; thus, that the correlation is due to chance alone is less than either $5 \%(\mathrm{p}<.05)$ or $1 \%(\mathrm{p}<.01))$

As shown in Table 2, all the well-being subscales correlated significantly with one another. The strongest correlations in the Ryff Well-being subscales is for SelfAcceptance, followed by Purpose in Life and Environmental Mastery. Of interest is that Autonomy had the lowest correlations with living according to one's values and hope scores.

Table 2: Pearson Correlations between the Well-being Scores

Agency Pathway Progress Obstruct




\begin{tabular}{lllll}
\hline & Hope & Hope & Values & Values \\
\hline Autonomy & $.386^{* *}$ & $.374^{* *}$ & $.263^{* *}$ & $-.416^{* *}$ \\
Environ Mastery & $.666^{* *}$ & $.520^{* *}$ & $.651^{* *}$ & $-.664^{* *}$ \\
Personal Growth & $.543^{* *}$ & $.522^{* *}$ & $.459^{* *}$ & $-.270^{* *}$ \\
Positive Relations & $.430^{* *}$ & $.351^{* *}$ & $.443^{* *}$ & $-.295^{* *}$ \\
Purpose in Life & $.716^{* *}$ & $.532^{* *}$ & $.611^{* *}$ & $-.534^{* *}$ \\
Self-Acceptance & $.750^{* *}$ & $.575^{* *}$ & $.660^{* *}$ & $-.598^{* *}$ \\
\hline Note. $* * p<.01$ & & & &
\end{tabular}

Note. $* * p<.01$

Second, the Depression, Anxiety and Stress scores were explored. As shown in Table 3, 68\% of participants did not report any major signs of Depression (with $15 \%$ reporting some major symptoms); $69 \%$ did not report any major signs of Anxiety (with 13\% reporting some major symptoms); and 57\% did not report any major problems with Stress (with $14 \%$ reporting some major symptoms. For the $57 \%$ of respondents that reported low or no stress, these were assigned to the No Stress Group, with the remaining $43 \%$ assigned to the Stress Group. Next, two t-tests were conducted comparing the two groups for depression and anxiety. Not surprisingly, those in the No Stress Group scored significantly lower on anxiety $(\mathrm{M}=2.14, \mathrm{SD}=$ 3.61) and depression $(\mathrm{M}=4.54, \mathrm{SD}=6.31)$ than the Stress Group (anxiety: $\mathrm{M}=11.29$, $\mathrm{SD}=8.42, \mathrm{t}(92.38)=-8.79, \mathrm{p}<0.001 ;$ and depression: $\mathrm{M}=16.91, \mathrm{SD}=12.38$ $\mathrm{t}(102.04)=-7.93, \mathrm{p}<0.001)$

Table 3: Percentage of scores based on the DASS-21

\begin{tabular}{cccccccc}
\hline & $M$ & $S D$ & Normal & Mild & Moderate & Severe & Extremely Severe \\
\hline Depression & 9.69 & 11.12 & $68 \%$ & $6 \%$ & $9 \%$ & $5 \%$ & $11 \%$
\end{tabular}




\begin{tabular}{lrrrrrrr}
\hline Anxiety & 5.98 & 7.52 & $69 \%$ & $5 \%$ & $13 \%$ & $6 \%$ & $7 \%$ \\
& & & & & & & \\
Stress & 14.05 & 10.41 & $57 \%$ & $15 \%$ & $14 \%$ & $8 \%$ & $6 \%$ \\
\hline
\end{tabular}

Third, hope and living according to one's values were explored. On average, Law Teachers were hopeful of the future - they scored 24 out of a possible score of 32 on Agency Hope (knowing that one has the abilities to do what one wants to do in the future) and 23 out of 32 on Pathways Hope (knowing that one knows how to get there in the future). Further, on average Law Teachers were moderate (16/30) on making progress towards valued goals and less likely to feel obstructed from valued goals (9/30). Next, a series of independent samples t-tests were conducted to compare those reporting No Stress with those reporting Stress for the hope and valuing scores. As seen in Table 4, those reporting stress also reported significantly lower scores in both agency and pathway hope, as well as progress towards and obstructed from values.

Table 4: The Hope and Valuing Subscales compared for the No Stress and Stress Groups.

\section{Stress Levels}

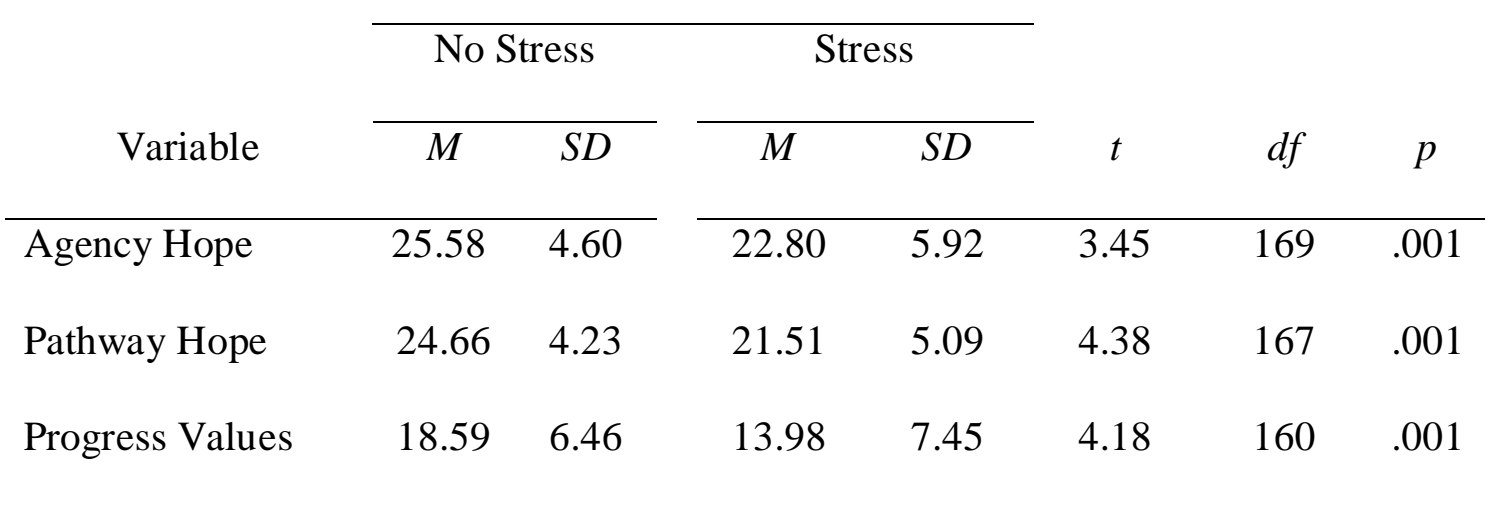




\begin{tabular}{llllllll}
\hline Obstruct Values & 6.29 & 4.78 & 14.18 & 6.09 & -8.83 & $116.8^{*}$ & .001
\end{tabular}

*failed Levene's Test for Equality of Variances, which means the variances are not equal so a minor mathematical correction has been made.

Fourth, Ryff's Psychological Well-being subscales were explored. The Law Teachers scored highest on Personal Growth, Positive Relations with Others and Purpose in Life, and lowest on Environmental Mastery, Self- Acceptance and Autonomy. Next, a series of independent samples t-tests were also conducted to compare those reporting No Stress with those reporting Stress for the six Ryff Psychological Well-being subscales. As seen in Table 5, those reporting stress also reported significantly lower scores in the Autonomy, Environmental Mastery, Positive Relationships and Self-Acceptance subscales of Well-being.

Table 5: The Ryff Well-being Subscales compared for the No Stress and Stress Groups.

\begin{tabular}{|c|c|c|c|c|c|c|c|}
\hline \multirow[b]{3}{*}{ Variable } & \multicolumn{4}{|c|}{ Stress Levels } & \multirow[b]{3}{*}{$t$} & \multirow[b]{3}{*}{$d f$} & \multirow[b]{3}{*}{$p$} \\
\hline & \multicolumn{2}{|c|}{ No Stress } & \multicolumn{2}{|c|}{ Stress } & & & \\
\hline & $M$ & $S D$ & $M$ & $S D$ & & & \\
\hline Autonomy & 60.16 & 7.45 & 56.71 & 9.95 & 2.09 & $79.96^{*}$ & .040 \\
\hline Environmental & 61.61 & 8.56 & 50.33 & 12.77 & 5.29 & $70.26^{*}$ & .001 \\
\hline \multicolumn{8}{|l|}{ Mastery } \\
\hline Personal Growth & 68.01 & 8.52 & 66.45 & 9.41 & .91 & 113 & .360 \\
\hline
\end{tabular}




\begin{tabular}{|c|c|c|c|c|c|c|c|}
\hline Positive & 62.79 & 9.41 & 58.34 & 11.76 & 2.20 & $82.24 *$ & .030 \\
\hline \multicolumn{8}{|l|}{ Relationships } \\
\hline Purpose Life & 65.46 & 9.46 & 61.11 & 13.19 & 1.94 & $71.03^{*}$ & .057 \\
\hline Self-Acceptance & 64.25 & 10.42 & 56.42 & 14.66 & 3.20 & $74.48 *$ & .002 \\
\hline
\end{tabular}

Fifth, to test the hypothesis that Depression, Anxiety, Stress, Hope and Valuing would predict the degree of Self-Acceptance and the degree of Purpose in Life, two regression analyses were conducted. The Self-Acceptance model was significant (adjusted $r^{2}=.713, F=41.049, p=.0001$ ). Five of the predictors were significant: Anxiety $(\beta=-.294, p=.001)$; Stress $(\beta=.212, p=.025)$; Agency subscale of Hope $(\beta=.330, p=.0001)$; Progress subscale of Valuing $(\beta=.303, p=.0001)$; and the Obstruction subscale of Valuing $(\beta=-.199, p=.027)$. The Purpose in Life model was also significant (adjusted $r^{2}=.661, F=31.946, p=.0001$ ). Four of the predictors were significant: Depression $(\beta=-.379, p=.002)$; Stress $(\beta=.252, p=.016)$; Agency subscale of Hope $(\beta=.327, p=.001)$; and the Progress subscale of Valuing $(\beta=.246, p=.001)$.

\section{CONTENT ANALYSIS OF OPN-ENDED QUESTIONS}

First, the response to the question 'How do you define your own stress and/or well-being?' was analysed. For the definitions of Stress, 98 participants responded with definitions of some sort (17 reported that either no stress in their work or that it was managed exceptionally well). The definitions included: Emotional/ physical 
definitions (e.g., anxiety, tiredness, feeling pressure, lack of sleep) 36\%;

Incompetency concerns (e.g., too much to do, and unrealistic expectations from self, university or students) 36\%; Lack of Autonomy (e.g., feeling out of control, not coping, overwhelmed by demands) $25 \%$; No work/life balance (e.g., work overshadows life even when at home) 15\%; Bad relationships with co-workers (e.g., feeling bullied by management) 9\%; Meaningfulness altered (e.g., little focus on what's important, use to be meaningful, now not) and Lack of job security (e.g., being pushed out of the job; wants to leave but nowhere to go) $2 \%$. For definitions of Wellbeing, 62 participants responded and the main definitions were: Competency (e.g., getting things done well) 29\%; Emotional (e.g., seeing well-being as happy mood) 27\%; Good balance (e.g., good work / life balance) 24\%; Autonomy (e.g., being/ feeling in control of work) $21 \%$; Meaningful work (e.g., enjoy and feel fulfilled by what you do) 16\%; and Good work relationships (e.g., get on well with others) $8 \%$.

Second, in response to the question 'If you felt you needed it, where would you seek help for your stress and/or lack of well-being?' 119 participants responded to this question (sometimes with multiple options for help), with the majority (63\%) reporting family and/or friends as their source of support for help with stress; the next category was talking to professionals ( $53 \%$ of which $59 \%$ were G.P.'s, followed by counsellors; generic health professionals and spiritual advisors/vicar). Interestingly $6.7 \%$ reported techniques such as massage, meditation and yoga, while $7.5 \%$ reported they did not know where they might seek appropriate help.

Third, the type of issues that students asked staff to help with was explored. There were 104 participants who answered this question. A wide range of issues were reported, including: Accommodation issues; Finance/ Debt issues; Academic issues (study / workload/ assessment issues or falling behind with work); Issues regarding 
future prospects; Academic misconduct; Personal issues (e.g., making friends); Health issues (e.g., pregnancy, illness); and Mental Health issues (including homesickness).

Fourth, student issues that staff felt capable of handling were explored (100 participants answered this question). The majority (78\%) reported that they were happiest dealing with academic and learning-related enquires. Interestingly, $32 \%$ were also happy to discuss other issues with their students as they were confident in their ability to refer problems on to other professionals. Further, approximately $14 \%$ reported that they were happy to support students who wanted to talk about personal issues (indeed, two participants reported they were trained in counselling). Note, they could give more than one response to this question.

Those issues with which staff felt they needed help could be grouped into two main areas: mental health problems and serious personal issues (divided further into emotional and financial issues). Finally, the topics that the staff felt they should not have to help with were predominately mental health problems. However, there was a sharp division of views about only wishing to deal with academic questions and not minding being the first port of call for all issues (but referring on when appropriate).

\section{DISCUSSION}

The current study gives an interesting picture of well-being in law academics. First, depression, anxiety and stress consistently significantly correlated with the same three variables - a strong positive correlation with obstructed values; and strong negative correlations with environmental mastery and self-acceptance. In other words Law Teachers who reported higher levels of depression, anxiety and stress also 
experienced an inability to live according to their values, little ability to control their environment around them and they tended to blame themselves.

Second, for the Ryff well-being factors, self-acceptance and purpose in life showed the highest correlations with the hope variables and the values (progress and obstruction). Thus Law Teachers who had goals and felt competent to achieve those goals and were able to live their values were significantly more likely to feel good about themselves and where they were going in life.

Third, overall most of the current sample did not report significant symptoms of Depression or Anxiety (although stress levels were generally higher).

The sample was split into two groups (Stress and No Stress) to explore the impact of stress for this sample. Not surprisingly, high stress levels were associated with higher anxiety and depression. The Stress Group also reported significantly higher obstructed values scores, and significantly lower progress on values scores, hope scores, lower autonomy, environmental mastery, positive relationships and selfacceptance (with no significant difference on personal growth or purpose in life). Thus this group of Law Teachers were vulnerable to feelings of being out of control and powerlessness and also to feelings of isolation and personal dissatisfaction.

Fourth, factors were explored that might best predict self-acceptance and purpose in life. Indeed, both self-acceptance and purpose in life were predicted positively for stress, agency hope and progress towards values but negatively for anxiety for self-acceptance; and negatively for depression for purpose in life. Those who were happier with who they were and had clear life objectives tended to experience stress but less anxiety than others, and, as they had the ability to work towards personal objectives, they felt that their lives were filled with meaning. 
Higher Stress, the UCU survey of stress and well-being among staff in Higher Education $2014^{30}$ reported that

"There is evidence that the rising level of stress in universities and colleges in the UK is due to the intense and wide-ranging changes experienced in the sector, which have resulted in increasingly complex, demanding and unpredictable working environments."

The report details ${ }^{31}$ the complex changes that the HE sector is undergoing that impact upon the work environment of all academic staff.

"Following extensive consultation, the HSE selected several elements of work activity (known as psychosocial hazards) that are:

a) considered relevant to the majority of UK employees; and b) have a strong evidence base as the most critical predictors of employee well-being and organisational performance. ${ }^{32}$ The specified hazards are demands, control, social support (from managers and peers), interpersonal relationships, role clarity, and involvement in organisational change."

The present study has found similar findings. Participants' definition of stress included: too much to do, feeling out of control, over-whelmed by demands, and bad relationships with co-workers. However, Kinman \& Wray ${ }^{33}$ did not explore flourishing (positive well-being) alongside depression, anxiety and stress. Indeed, in the present study, stress also positively predicted self-acceptance and purpose in life. Thus, eliminating stress altogether may not be desirable (although all indications from the present data suggest that eliminating depression and anxiety would be excellent). Thus, exploring stress alone may give a limiting picture and some stress relating to

\footnotetext{
30 Kinman, op. cit., n.7, p5

${ }^{31}$ Kinman, id., p7

${ }^{32}$ Kinman id referring to C. J. MacKay, et al. 'Management Standards' and work-related stress in the UK: Policy background and science' (2004) 18.2 Work \& Stress 91-112

${ }^{33}$ Kinman, op. cit., $\mathrm{n} 7$
} 
the good things in life would not enhance one's life if it were eradicated. However, where it relates to obstruction of one's values, and lack of control over one's life, then stress erodes well-being.

Self Determination Theory indicates that human psychological needs include autonomy, competence and relatedness. In relation to law teachers, autonomy is to be examined in the context of the employment relationship because the employees have less power than the employer. As explained by Krieger, ${ }^{34}$ autonomy support in lawyers (and replicating results in Krieger's law student study in $2007^{35}$ ) has a strong correlation with well-being. It requires the person in control to be sensitive to the views of the managed and if choice cannot be offered then an explanation should be given as to why there can be no choice. It does aid autonomy if the academic in this situation is able to align personal values with the fait accompli. In response to the open-ended question on stress and well-being, 25\% reported a lack of autonomy in relation to stress and positive aspects of autonomy were reported in $21 \%$ of participants' definitions of well-being. This suggests some importance of autonomy to academic staff.

Law Teachers may be aware of principles of positive psychology and have recognised the concept of personal values and character strengths. This group may use their own personal goals in such a way that they are finding meaning in their work and lives. There is research from the Jubilee Centre for Character and Virtue ${ }^{36}$ that provides some data that is worth discussing. The Jubilee Centre data reports on the

\footnotetext{
${ }^{34}$ L. S. Krieger, and K. M. Sheldon 'What makes lawyers happy?: A data-driven prescription to redefine professional success' (2014) 83 Geo. Wash. L. Rev. 554.

${ }^{35} \mathrm{~K}$. M. Sheldon, and L. S. Krieger, 'Understanding the negative effects of legal education on law students: A longitudinal test of self-determination theory' (2007) 33 Personality and Social Psychology Bulletin 883-897

36 Arthur, J., Kristjansson, K., Thomas, H., Holdsworth, M., Confalonieri, L.B. and Qiu, T. (2014) Virtuous Character for the Practice of Law. Project Report. University of Birmingham, Birmingham.

< http://www.jubileecentre.ac.uk/1553/projects/grati>
} 
results of a "UK-focussed survey of 966 lawyers and aspiring lawyers at varying stages of their careers" ${ }^{, 37}$ and include questions about personal and ideal lawyer virtues. The data provides an indication of the importance of fairness for the four groups of legal profession: first year undergraduates, students undertaking the vocational course, solicitors and barristers. "Fairness, honesty, humour and perseverance" were the personal virtues most commonly reported. ${ }^{38}$ There was closer agreement of virtues for the ideal lawyer and these were "Judgement, honesty, perseverance, fairness and perspective". ${ }^{39}$

The Jubilee data suggests that those Law teachers (defined for the purpose of this argument as former law students) who have a personal value of fairness may struggle with maintaining well-being if the processes of their institution are not perceived as fair and if there is insufficient explanation and or meaningful choice in those processes perceived to be unfair (such as workload models "too many things to do at once and not enough time to do it", "work inappropriately allocated so there is now no down-time" or the distribution of tasks between administrators and academics, "I can see a senior management narrative emerging that pins failings on academics" ${ }^{40}$ ). According to SDT in circumstances such as these autonomy support is absent.

Environmental mastery is not the same as autonomy but linked superficially and encompasses the ability to manage environments according to one's needs and values. "The emphasis on finding or creating a surrounding context that suits one's personal needs and capacities is unique to environmental mastery", ${ }^{41}$ Those with reduced scores in this area may feel unable to cope with demands placed upon them.

\footnotetext{
37 Arthur, id., p5

${ }^{38}$ Arthur, id., p15

${ }^{39}$ Arthur, id

${ }^{40}$ These quotes are composites of comments made in the survey.

${ }^{41}$ C. D. Ryff, and B. H. Singer 'Know thyself and become what you are: A eudaimonic approach to psychological well-being’ (2008) 9 The Journal of Happiness Studies 13 - 39
} 
Many Universities are asking staff to achieve more and can cause this feeling of being out of control if this is not managed in a supportive atmosphere. Not surprisingly, the present study showed this factor was important with low levels associated with high depression, anxiety and stress scores and high levels associated highly with the wellbeing measures. "Research findings... demonstrate that the features that traditionally protected employees working in universities and colleges against work-related stress, such as job control and support, have gradually eroded, thus exacerbating the pressure experienced by employees" ${ }^{42}$ Autonomy, respect and fair treatment from managers appear to protect academics from the negative impact of even heavy job demands on non-working life ${ }^{43}$. If, as suggested by the Jubilee data, many Law Teachers value fairness, a perceived lack of fair treatment could be of more significance to this group of academics.

Competency can also be seen in relation to the response to the open-ended question in the present study on stress and well-being, with $36 \%$ associating feelings of low competency (inability to do a good job due to work demands) with stress and $29 \%$ reporting knowing/ feeling they were competent in their jobs as a main source of well-being. Higher Education in the UK has undergone a radical transformation in the past decade: the nature of role and demands have changed; there are increased student numbers and new notions of student contracts with universities, students are paying increased fees and there is increased competition between Universities for student numbers; growing importance is being placed on national and global rankings; and there is more regular curriculum redesign with demands for more diverse modes of delivery; finally academics are faced with institutional performance management

\footnotetext{
${ }^{42}$ G. Kinman and S.Wray 'Taking its Toll: Rising Stress Levels in Further Education’ (2014) UCU Publications. P6 Available online at:

$<$ http://www.ucu.org.uk/media/pdf/q/b/ucu_festressreport14.pdf?CFID=22923281\&CFTOKEN=47794 b65a042a5a-A97173F8-AEFD-756C-7658Dי $963909 F B 278>$

${ }^{43}$ Kinman,id.
} 
structures, and demands for excellence in both teaching and research and to boost income. This cultural and structural change is well documented. ${ }^{44}$ Together these factors may be decreasing perceived competency in the ever-changing job of an academic.

Darabi, Macaskill and Reidy ${ }^{45}$ reporting on qualitative data collected from 31 Sheffield Hallam academics noted a possible reason for low perceptions of competence:

"Heavy workloads are identified as another stressor at work as academics feel that they cannot deliver as well as they would like. Tytherleigh et al. ${ }^{46}$ reported similar findings of stress linked to heavy workloads and resultant dissatisfaction as academics have insufficient time to perform to the standard they would wish."

The survey in the present study indicates that academics want to do a better job - hence they begrudge their time being taken up in ways they think are not valuable. Academics want to give more time to students and they want to give more time to their research. The changing and increasing demands experienced by academics at work appear to explain changes to their perceptions of competency and this could be a source of reduced feelings of well-being.

Reduction in positive relationships was also reported in the definitions of stress and well-being but at lower levels. Staff were indicating that they seek support

\footnotetext{
${ }^{44}$ K. Sang, A. Powell, R. Finkel, \& J. Richards, 'Being an academic is not a 9-5 job': long working hours and the 'ideal worker'in UK academia' (2015) 25(3) Labour \& Industry: a journal of the social and economic relations of work 235-249. See also Baron, op. cit., n. 2

${ }^{45}$ M. Darabi, A. Macaskill, \& L. Reidy 'A qualitative study of the UK academic role: positive features, negative aspects and associated stressors in a mainly teaching-focused university' (2016) Journal of Further and Higher Education, 1-15 p12

${ }^{46}$ Darabi, id referring to M. Y. Tytherleigh, C. Webb, C. L. Cooper, C. Ricketts 'Occupational stress in UK higher education institutions: A comparative study of all staff categories' (2005) 24(1) Higher Education Research \& Development 41-61.
} 
for stress from contacts outside work and stress is sometimes the result of inept management, a bullying culture or co-workers unwilling to co-operate. Thus, reduced collegiality may be an important theme. Relatedness forms one of the key psychological needs according to self-determination theory. People are more likely to thrive if they are forming positive relationships and bonds of trust with others.

Increased expectations from self, University, and students may lead academics to seek to control their working environment and to prevent unplanned interruptions by working in isolation. This hinders building relationships with work colleagues.

The ability to build collegiality at work may be more difficult for law teachers than for other academics. A substantial proportion of the survey population are likely to have a professional practitioner background. Many will have practised as Solicitors and Barristers before moving into Higher Education and chosen to change profession. This career change, especially if done by those without doctoral degrees, may result in lower perceptions of competence and perceptions of a division between former practitioners and staff with doctorates.

Lawyers are generally considered to be perfectionists. ${ }^{47}$ Vulnerability to perceptions of lower competency may be a factor more commonly associated with those who choose to study law as a result of this trait. The Jubilee data indicates the character strength of perseverance was in the top six virtues both as an ideal and as a personal trait. This may indicate lawyers are perfectionist or it may indicate that they are obstinate.

The Student Mental Health Report discusses perceptions of the impact of increased disclosures of mental health issues by students on academics in section 5 . Academics' perceptions, from those who had worked for some years in HE, confirm

\footnotetext{
${ }^{47}$ C. James 'Law Student Well-being: Benefits of Promoting Psychological Literacy and SelfAwareness Using Mindfulness, Strengths Theory and Emotional Intelligence' (2011) 21(2) Legal Education Review 217-232
} 
that these disclosures have increased in volume and in severity of issue. Many academic participants reported that they found it difficult to 'switch off' from these problems.

"Responding to the range and complexity of issues that students present to academics, was seen to have ongoing cognitive, emotional, relational and practical effects." 48

The report suggests as one of its eleven recommendations that clarifying the role of academics in supporting students with mental health would address current uncertainty and reduce risk of distress in academics. The findings in this report and its' suggestion about the role of academics align with the discussion herein of the qualitative data in relation to Law Teachers. The definition of stress given by Law Teachers included a lack of work/life balance with work overshadowing life even when at home. Furthermore, neither lawyers nor academics are experts in mental health issues or counselling and the increased student disclosures may well impact upon their perceptions of competency.

\section{CONCLUSION}

This study provides evidence that changing and increasing expectations of University, of students, and of academics of themselves has had an impact upon the perceptions of well-being in the Law Teachers who responded to this survey. Self Determination Theory proposes that everyone needs to experience autonomy, competence and relatedness in order to thrive. The results reported here indicate the importance of autonomy to Law Teachers. The results indicate the desire to have personal perspectives recognised and a clear rationale for the fait accompli.

\footnotetext{
${ }^{48}$ Hughes, op cit., n9, p42
} 
Demanding workloads, possible career change, and increased disclosures by students of significant personal issues impact on feelings of competency. Reaction to increased role demands including increased student numbers may account for feelings of reduced relatedness and collegiality. Fortunately the majority of participants did not report significant symptoms of depression, anxiety or stress. However, this is an issue that requires further investigation because of the potential for levels of psychological distress to increase. The Times Higher Education reported on the result of a work-life balance survey early in $2018^{49}$ that reported "ever-growing workloads" being experienced in Higher Education in the UK and beyond.

There are limitations to the conclusions that can be drawn from the data. The number of participants form a small percentage of the overall population of law teachers. The participants are reporting on their personal views and this limits the objectivity of the data. Nonetheless, this data can form something of a benchmark for comparative purposes when used with subsequent data collections. The $2017 \mathrm{Law}$ Teachers survey is currently being analysed by the authors. Furthermore the 2017 survey has been duplicated in a survey of Australian Law Teachers and a comparative analysis is forthcoming.

The data analysed in this paper does not provide evidence of a causative link between negative stress and the elements of psychological well-being. Rather, correlations have been explored. This is a complex issue and only general recommendations for interventions to support academics in Law Schools can be made. Firstly, the support mechanisms that many Universities have put in place to address the health and well-being of students should be extended to academic staff and this could include examining the impact of increasing workloads. The concept of

\footnotetext{
${ }^{49}$ See P Jump <https://www.timeshighereducation.com/features/work-life-balance-survey-2018-longhours-take-their-toll-academics>
} 
autonomy support ${ }^{50}$ could be better understood and deployed in Law Schools in the management of academics. The impact on academics of disclosures by students of significant personal issues should be recognised. Role boundaries should be clarified and training provided to reduce feelings of lack of competency. Finally, in order to build community, a culture of mutual support should be encouraged.

A recent systematic review of the literature on interventions at University to support the mental health of academics produced disappointing results ${ }^{51}$

"There is a lack of information with regard to interventions directed at employees. The results suggest that policies that successfully promote the mental well-being of university staff include the involvement of employees in decision making and provide opportunities to increase employees' knowledge of mental health and well-being. Unfortunately, the number of studies found was low and the quality of the evidence was poor, prohibiting any strong recommendation."

There are many reports both within the Higher Education sector and beyond calling for a greater understanding of self-regulation so that everyone is able to manage their personal resilience to stress and maintain psychological well-being. This should extend to academic staff. In the context of Law Schools empirical research, although being challenged, ${ }^{52}$ is highlighting a particular issue of high levels of psychological distress in law students in their first year of study. Thus, it is argued, that investigating well-being in Law Teachers has potential significance for the next generation of practitioners and academics who are likely to begin their careers as law

\footnotetext{
${ }^{50}$ For a full discussion of autonomy support see L. S. Krieger, \& K. M. Sheldon, op.cit., n34

${ }^{51}$ A. Fernandez, E. Howse, M. Rubio-Valera, et al. 'Setting-based interventions to promote mental health at the university: a systematic review' (2016) 61 Int J Public Health 797.

${ }^{52}$ C. Parker, 'The Moral Panic over Psychological Well-being in the Legal Profession: A Personal or Political Ethical Response' (2014) 37 UNSWLJ 1103.
} 
students. If Law Teachers are to promote student well-being then it is essential that they are able to understand and effectively manage their own.

Acknowledgement: Thanks to the many legal academics in the UK who agreed to take part in this research. The research was supported by a Legal Education Research Network (LERN) grant awarded to the two authors. All enquiries should be addressed to Dr. J. Clare Wilson, Department of Psychology, University of Portsmouth, Portsmouth, PO1 2DY, UK Phone: 44-23-92846305. Email:clare.wilson@port.ac.uk

Disclosure statement

No potential conflict of interest was reported by the authors 